\title{
REFLEXÕES SOBRE A EMPREGABILIDADE DOS JOVENS PROVENIENTES DE CURSOS SUPERIORES DE TECNOLOGIA
}

\author{
REFLECTIONS ON EMPLOYABILITY OF YOUNG PEOPLE FROM \\ PROFESSIONAL HIGHER EDUCATION
}

Recebido em 16.08.2016. Aprovado em 12.01.2017
Avaliado pelo sistema double blind review
DOI: http://dx.doi.org/10.12712/rpca.v11i1.801

\section{Bibiana Volkmer Martins}

bibivolkmer@hotmail.com

Universidade Federal do Rio Grande do Sul (UFRGS), Porto Alegre/RS, BRASIL

\section{Sidinei Rocha de Oliveira}

sidroliveira@hotmail.com

Universidade Federal do Rio Grande do Sul (UFRGS), Porto Alegre/RS, BRASIL

\section{Resumo}

Nas últimas duas décadas o mundo do trabalho tem passado por inúmeras transformações, entre elas a crescente flexibilização das suas relações, o que têm afetado sobremaneira grupos mais vulneráveis como os jovens, mesmo que não de forma homogênea, já que se entende existirem múltiplas juventudes no país. Paralelamente, ocorreu uma expansão sem precedentes do ensino superior profissional no Brasil, que estabelece raízes na ressignificação da teoria do capital humano. Apesar da predominância do discurso de equivalência entre formação e emprego, aquela já não se apresenta como garantidora da entrada no mercado de trabalho. Assim, este ensaio teórico busca discutir a relação entre a profissionalização do ensino superior no Brasil e a empregabilidade dos jovens, bem como estabelecer uma agenda de pesquisa para estudos sobre o tema. Para tanto, parte-se de estudos franceses sobre a expansão e profissionalização do ensino superior, uma vez que este processo já se consolidou nesse país, com vistas a avançar nas reflexões sobre a temática no Brasil.

Palavras-chave: Cursos superiores de tecnologia. Mercado de trabalho. Empregabilidade. Inserção profissional. Jovens.

\begin{abstract}
In the last two decades labour's world undergoes through many changes, including an increasing in flexibility of their relations. These changes have affected the most vulnerable groups such as young people, even if not homogeneously, since it is understood that there are multiple youths in the country. At the same time, there was an unprecedented expansion of professional higher education in Brazil, rooted in the reinterpretation of the human capital theory. Despite the predominant discourse of equivalence between education and employment, qualification is no longer a guaranty of entrance into the labor market. Thus, this theoretical essay discusses the relationship between professional higher education in Brazil and the employability of young people, proposing a research agenda for future studies on the subject. Therefore, intending to advance on this subject in Brazil, this paper is based on studies about the expansion and professionalization of higher education in France, since this process has already been consolidated in that country.
\end{abstract}

Keywords: Professional Higher Education. Labor Market. Employability. Professional Insertion. Young People. 


\section{Introdução}

Desde a década de 1990, mudanças resultantes do projeto de reestruturação produtiva trouxeram significativas transformações para o mundo do trabalho. Entre elas, pode-se citar a integração à esfera do trabalho de inovações tecnológicas, novas formas de organização como a produção enxuta, e a crescente internacionalização e desterritorialização dos mercados. Transformações sociais como a liberalização econômica e a diversificação da mão de obra levaram a modificações profundas nas formas dos contratos sociais entre organizações e trabalhadores. Ocorreram demissões em massa, o emprego foi precarizado (temporário, por conta própria, partilhado, terceirizado, etc.), bem como se passou a exigir uma polivalência funcional (ROCHADE-OLIVEIRA; PICCININI, 2011), de modo a acompanhar as modificações constantes no mundo do trabalho.

No Brasil, entre as transformações se destacam a flexibilização dos contratos e uma significativa desindustrialização dos empregos, que derivou no crescimento do setor de serviços e do trabalho por conta própria (SCALON, 2009). Além disso, apesar de ter havido uma expansão quantitativa de ocupações nos anos 2000, com saldo líquido 44\% superior ao verificado no período entre 1980 e 1990, os novos postos de trabalho se concentraram, em sua maioria, na base da pirâmide social, já que $95 \%$ das vagas abertas apresentaram remuneração de até 1,5 salários mínimos (POCHMANN, 2012). Para Guimarães dos Santos (2013), grande parte dos empregos que surgiram foram de curta duração, sem muitas garantias sociais e habitualmente de baixa remuneração. Situação que reverbera a conjuntura mundial do mercado de trabalho, o qual não apresenta iguais possibilidades de ascensão social ou até mesmo de trabalho decente que ofereceu nas três décadas seguintes à Segunda Guerra Mundial (GUIMARÃES DOS SANTOS, 2013).

Somado a isso, a partir de 2014 a política econômica nacional mudou de rumo, invertendo assim a trajetória do desemprego. As políticas de ajuste econômico realizadas em 2015 resultaram no reaparecimento da recessão, que teve efeitos sobre o mercado de trabalho e, sobretudo, sobre as taxas de desemprego, que chegou a 11,9\% em novembro de 2016 (IBGE, 2016). Ademais, nota-se a redução do rendimento médio real recebido pelos trabalhadores, o que tende a gerar, segundo Pochmann (2016) o acirramento da competição entre os indivíduos, tanto para os que perdem o emprego, quanto para aqueles que estão buscando se inserir no mercado de trabalho.

Nesse cenário, tanto jovens como adultos têm competido de modo desigual pelos empregos existentes (GUIMARÃES DOS SANTOS, 2013). Todavia, segundo Rocha (2008), apesar de o desemprego atingir a todos, são os jovens que enfrentam maiores dificuldades de colocação, haja vista a sua vulnerabilidade às adversidades do mercado de trabalho, em virtude de características como a falta de experiência e a busca por experimentação. De acordo com Guimarães (2013) os jovens compõem um segmento que estabelece maciçamente vínculos de trabalho temporários, os quais chegaram, no Brasil, a $60 \%$ do tipo de vínculos estabelecidos por esse grupo no ano de 2010. Além disso, dados da Pesquisa Nacional por Amostra de Domicílios (PNAD) referentes aos anos de 2014-2015 demonstram 21,3\% de taxa desocupação entre os jovens de 18 a 24 anos, ao passo que entre os indivíduos de 25 a 49 anos essa taxa é de 7,8\% (PNAD, 2015). Além disso, os jovens de 15 a 24 anos aumentaram de janeiro a julho de $2015 \mathrm{em} \mathrm{43,4 \%}$ a sua taxa de desemprego, que apesar de percentualmente ter ficado um pouco abaixo do aumento de $44,2 \%$ dos indivíduos de 25 a 49 anos, representou em termos de taxa relativa à porcentagem de 18,5\%, enquanto os últimos apresentaram 6,2\% (POCHMANN, 2016).

Em que pese o entendimento dos jovens entre os grupos mais vulneráveis no mundo do trabalho, se faz mister ressaltar que ele não é homogêneo e comporta o que Rocha-de-Oliveira, Piccinini e Bitencourt (2012) intitulam de múltiplas juventudes, ou seja, a existência, conforme destaca Galland (2001), da fragmentação das trajetórias juvenis. Assim, os indivíduos pertencentes a uma mesma geração ${ }^{1}$, neste caso a de jovens, mais do que compartilharem um marco temporal, representam também um processo histórico e uma situação de classe (TOMIZAKI, 2010), aos quais se acrescentam aqui, elementos apontados por Souza (2012) como transclassistas ${ }^{2}$, tais como sexo e raça.

\footnotetext{
${ }^{1}$ Mais sobre o conceito de geração por der lido em Tomizaki (2010)

${ }^{2}$ Que atravessam as classes e implicam em heterogeneidades dentro de uma mesma classe (SOUZA, 2006).
} 
Ademais, se a classe for entendida nos termos de Souza (2012) e Bourdieu (2015) como práticas sociais e culturais similares, outros elementos como o conjunto de capitais possuídos (cultural, econômico, social), profissão, renda, nível de instrução, origem social e gostos (estilos de vida) são elencados para definir a trajetória individual dos jovens. Assim, conforme retrata Volkmer Martins (2016) em pesquisa realizada junto a jovens estudantes e egressos de cursos superiores de tecnologia na região metropolitana de Porto Alegre, elementos de classe (inclusive a de origem), raça e sexo refletem no processo de inserção profissional dos jovens, constituindo-o como um período heterogêneo.

Paralelamente, no Brasil, os últimos 15 anos têm sido marcados pela expansão sem precedentes do ensino superior, a qual tem se caracterizado, entre outros fatores, pela profissionalização desse nível do ensino por meio da crescente inserção de cursos superiores de tecnologia (CSTs). O Censo de 2015, realizado pelo Instituto Nacional de Estudos e Pesquisas Educacionais Anísio Teixeira (INEP), registrou um total de 1.010.142 matrículas nessa modalidade de ensino, contra 42.852 registradas em 2004, representando $12,6 \%$ do total das matrículas em educação superior (INEP, 2004; 2015). Apesar de os CSTs datarem, no Brasil, da década de 1960 (BRASIL, 1968), é a sua expansão nos últimos anos que começa a chamar a atenção de pesquisadores. Contudo, por se tratar de um fenômeno recente, tal expansão e as suas repercussões ainda são foco de poucos estudos no Brasil, a maioria deles provenientes da área da educação.

Dentre os enfoques que vêm sendo trabalhados, alguns merecem destaque. Alguns autores têm se preocupado com a qualidade dos CSTs (GARIBA JÚNIOR, 2005; CAMPELLO et al., 2009), outros com os processos de transformação dos Centros Federais de Educação Profissional e Tecnológica em Institutos Federais (PIRES, 2006; CIAVATTA, 2006, ALMEIDA JUNIOR; PILATTI, 2007). Existem ainda estudos que focam na expansão dos CSTs como um processo de privatização contínua do ensino superior (SEGENREICH; CASTANHEIRA, 2009), outros que questionam o entendimento da proliferação dos CSTs como um processo de democratização do ensino superior (BRANDÃO, 2006). Um grupo mais reduzido tem se debruçado sobre a repercussão do aumento da oferta de CSTs para o mercado de trabalho, (NETO; MODESTO; ARGOLLO, 2009; ALMEIRA JUNIOR; PILATTI, 2007). Na área de Administração, Adriana Takahashi tem realizado pesquisas acerca da repercussão do aumento dos CSTs para o ensino superior brasileiro, bem como trabalhos sobre os processos de aprendizagem organizacional no desenvolvimento de competências em IES para a oferta de CSTs (TAKAHASHI, 2010).

Embora algumas pesquisas já estejam em andamento, ainda há um amplo campo para estudos que permitam compreender o gradativo crescimento desta modalidade dentro do ensino superior brasileiro. Ademais, nesse cenário, em que pesa a mudança na composição da força de trabalho no país, surgem novos desafios para a análise das relações que se estabelecem entre formação e trabalho.

Assim, este ensaio ${ }^{3}$ tem como objetivo discutir a relação entre o crescimento do ensino superior profissional no Brasil e a empregabilidade dos jovens, e estabelecer uma agenda de pesquisa para estudos sobre o tema. A orientação do trabalho para a formação de jovens deve-se a este ser um dos grupos mais afetados pelo desemprego e pelos impactos da flexibilização das relações de trabalho que segue em curso no país (GANZ LUCIO, 2013; GUIMARÃES, 2103; POCHMANN, 2013). Contudo, merece destaque, que se trata de um recorte de pesquisa de modo que os jovens constituem múltiplas juventudes.

Parte-se do entendimento que a expansão do ensino superior profissional no país estabelece raízes na ressignificaçãodateoriadocapitalhumano, deTheodore Schultz (1973), que entende a qualificação profissional como principal requisito para empregabilidade. Tal valorização da formação profissional como forma de fazer frente ao desemprego difundida no Brasil se atrela em grande medida ao debate internacional sobre a crise do mercado de trabalho (LEMOS; DUBEUX; PINTO, 2009). Para avançar nas reflexões existentes no país, propondo novos questionamentos, toma-se como base o quadro teórico francês sobre a expansão e profissionalização do ensino superior, uma vez que este processo já se consolidou neste país em décadas anteriores, já havendo uma série de estudos estruturados sobre as mudanças nas formas de trabalho, ampliação da formação e o processo de ingresso dos jovens no mercado de trabalho (ROCHADE-OLIVEIRA; PICCININI, 2012a).

\footnotetext{
${ }^{3}$ O presente trabalho foi realizado com o apoio CAPES, Coordenação de Aperfeiçoamento de Pessoal de Nível Superior - Brasil.
} 
Destarte, este estudo divide-se em mais quatro seções além desta introdução. A primeira aborda a relação entre mercado de trabalho e formação profissional. O segundo tópico traz alguns estudos franceses sobre a expansão e profissionalização do ensino superior na França. A terceira seção busca refletir acerca do crescimento do ensino superior profissional no Brasil e a empregabilidade dos jovens. Ao término, são apresentadas as considerações finais e a proposta de agenda de pesquisa.

\section{Mercado de Trabalho, Empregabilidade e Formação Profissional}

A qualificação profissional tem sido apontada como requisito para empregabilidade e vem constituindo-se como um desafio para aqueles que pretendem se inserir no mercado de trabalho. Os debates que envolvem as mudanças das relações laborais, principalmente a partir da década de 1990, têm sido pautados pelo destaque da necessidade de novos perfis profissionais que sejam capazes de dar conta desse novo contexto (LEMOS, DUBEUX e PINTO, 2009). Entende-se aqui, que tal debate finca suas raízes no renovado fôlego adquirido pela teoria do capital humano de Theodore Schultz (1973), da década de 1960.

Para Schultz (1973) os homens são capazes de adquirir conhecimentos e diversas habilidades que representam valor econômico, correlação que impõe um conceito integrado de capital. O ensaio de Schultz (1973, p. 13) fundamenta-se "[...] na proposição segundo a qual as pessoas valorizam as suas capacidades, quer como produtores quer como consumidores, pelo auto-investimento, e de que a instrução é o maior investimento no capital humano". Desse modo, Schultz (1973) postula que a maioria das habilitações econômicas dos indivíduos não é relativa "ao berço", mas é adquirida com a instrução ao longo da vida. Tais habilitações são capazes de alterar as estruturas de pagamentos de salários e dos ganhos do trabalho relativos ao montante do rendimento da propriedade. O componente da produção que decorre da instrução é, portanto, "[...] um investimento em habilidades e conhecimento que aumenta futuras rendas e, desse modo, assemelha-se a um investimento em (outros) bens de produção" (SCHULTZ, 1973, p. 23-24).

Lemos, Dubeux e Pinto (2009) postulam que no atual contexto de modificações no mundo do trabalho, o papel da educação estaria sendo revalorizado, apesar de apresentar bases diversas das da década de 1960, quando era associada ao crescimento econômico e à integração social dos indivíduos. Conforme os autores a crise do capitalismo avançado, possibilitou que a educação assumisse um novo papel, não mais de promover o desenvolvimento econômico, mas de aumentar as chances individuais de inserção no mercado de trabalho (LEMOS, DUBEUX e PINTO, 2009). Assim, em um contexto no qual o imperativo da competitividade alcança escala internacional, a mão de obra qualificada - subestimada no sistema taylorista-fordista - passa a ser valorizada como capaz de contribuir com as novas necessidades das empresas (CATTANI, 2011).

Takahashi (2010) entende que o fomento à educação profissional de nível superior, pelo qual tem passado o país nos últimos dez anos, é resultado: (i) da busca de continuidade dos estudos por formandos do ensino médio; (ii) da pressão da intitulada Economia do Conhecimento sobre os sistemas educacionais, com o intuito de formar e qualificar os trabalhadores para que as organizações insiram-se na economia globalizada; além (iii) da existência de uma tendência mundial de investimentos em educação profissional. Dentre os países que tem desenvolvido iniciativas de educação superior - com foco na aproximação de educação profissional e acadêmica - pode-se citar: Inglaterra, Estados Unidos, Japão, França, Alemanha, Suécia e Nova Zelândia (CORAIOLA; BARATTER; TAKAHASHI, 2013).

Esta mudança nas modalidades de formação insere-se em um contexto maior, decorrente da reestruturação produtiva e das modificações nas formas de organização do trabalho, entre elas a ressignificação da teoria do capital humano, que transfere a responsabilidade para o indivíduo por sua empregabilidade. Gary Becker (1993), ganhador do Prêmio do Banco Central da Suécia em homenagem a Alfred Nobel, utilizou a teoria como forma de justificar e explicar que a diferença de salários entre os trabalhadores era responsabilidade deles próprios. Tal visão entende que o aumento da formação leva ao aumento de salário, e que o investimento em formação cabe ao próprio trabalhador (CATTANI, 2011). Outros trabalhos como os de Soares e Gonzaga (1997) e Ferreira (2000), também buscam reforçar a relação entre capital humano, empregabilidade e renda.

Nesse cenário, questões relativas à educação e às políticas públicas de formação técnico-profissional têm sido tratadas no Brasil, diante da crise estrutural 
do desemprego e do desenvolvimento desigual, como intrinsecamente atreladas às mudanças no processo produtivo (FRIGOT'TO, 2011). Náder e Oliveira (2007) apontam que a qualificação da mão de obra entra para a ordem do dia sob a prerrogativa de que investimentos em qualificação além de servirem para aumentar a produtividade do trabalhador, também impeliriam o crescimento econômico, de maneira a contribuir para a redução do desemprego no país. Conforme Gentili (2011), para além de pensar a integração dos trabalhadores ao mercado de trabalho, as políticas educacionais começaram a voltar-se para a garantia da transmissão diferenciada de competências flexíveis, de modo a habilitarem os indivíduos a lutarem nos exigentes mercados laborais pelos poucos empregos disponíveis.

Nesse contexto, a noção de empregabilidade, entendida como capacidade individual de disputar as possibilidades limitadas de inserção oferecidas pelo mercado de trabalho e de se ajustar a ele ${ }^{4}$, ganha espaço e toma o lugar da garantia de emprego como direito social (NÁDER; OLIVEIRA, 2007; GENTILI, 2011). A empregabilidade passa, assim, a ser a propagada como a nova alternativa dos indivíduos e, na era do fim do trabalho ${ }^{5}$, a competência empregatícia flexível torna-se a possível garantia de sucesso no mundo laboral. Contudo, com um custo social que evidencia a natureza estruturalmente excludente dos novos tempos (GENTILI, 2011). Segundo Lemos, Rodrigues e Monteiro (2011, p. 597):

A ênfase dada à empregabilidade no debate contemporâneo sobre o mundo do trabalho desloca o eixo da responsabilidade pela geração de oportunidades de trabalho da sociedade para o indivíduo. Esse deslocamento não é sem custo para o trabalhador que sente o peso da responsabilidade sobre algo que, na maioria das vezes, tem pouca ingerência.

Dessa forma, nota-se um resgate da teoria do capital humano, mas com um novo sentido. Passou-se da lógica fundada nas necessidades e demandas de caráter coletivo - economia nacional, competitividade das empresas, riqueza social, entre outras - à lógica econômica unicamente privada e orientada “[...] pela ênfase nas capacidades e competências que cada pessoa deve adquirir no mercado educacional para atingir uma melhor posição no mercado de trabalho" (GENTILI, 2011, p. 81). O destaque dado à meritocracia individual no acesso dos jovens ao mercado de trabalho no país obscurece, assim, o desemprego como "[...] consequência da incapacidade do sistema capitalista de absorver os trabalhadores disponíveis", transferindo essa responsabilidade aos indivíduos e à sua suposta inadequação às exigências de qualificação do novo paradigma produtivo" (SILVA; COSTA; LEMOS, 2014, p. 2).

Para Peugny (2014), tal glorificação do mérito é consequência da invisibilidade social, já que é a partir da negação dos antagonismos sociais que cada um pode ser responsabilizado por suas escolhas, sucessos e fracassos de maneira individual. Responsabilização essa, que se dá apesar da redução das desigualdades quantitativas, pois são mantidas as desigualdades qualitativas, já que é ampliado o acesso ao nível de formação, mas nem todos têm acesso aos mesmos tipos de diplomas e carreiras profissionais (PEUGNY, 2014), perpetuando algumas formas de segregação no mercado de trabalho. Assim, o discurso meritocrático se apresenta como prejudicial às tentativas de superação das desigualdades sociais, pois ao se focar na qualificação para o mercado de trabalho não trata da reprodução das desigualdades sociais ao longo da vida dos jovens, as quais não se limitam ao momento de ingresso no nível superior, mas são reflexo da trajetória de cada um e do contexto de formação e oportunidades de trabalho que vislumbram e têm acessso. Conforme Peugny (2014) crianças advindas de meios sociais com pouco acesso a capitais econômicos e culturais estão, desde o início de sua trajetória, em desvantagem frente a outras.

Ademais, o discurso meritocrático vincula a educação à realidade mercadológica, dominando o sistema de ensino brasileiro e fazendo com que aumente a demanda das classes populares por educação. Esse quadro encontra sustentação nas novas tecnologias e na globalização da economia, que tendem a estabelecer

\footnotetext{
${ }^{4}$ Importante ressaltar que apesar de esta ser a noção hegemônica, ela não é a única de existe. Mais sobre empregabilidade em Náder e Oliveria (2007).

${ }^{5}$ Estamos cientes da diferença entre as noções de trabalho e emprego. A primeira é mais antiga e está atrelada à transformação da natureza por meio da técnica. Já o segundo conceito surgiu no século XX, no qual o trabalho assume forma de contrato, caracterizado pela relação de emprego (assalariado e estável) (ROCHA-DE-OLIVEIRA; PICCININI, 2011). Como os diversos autores misturam muitas vezes os termos utilizados, no artigo, quando falamos tanto de trabalho como de emprego, estamos nos referindo à relação de emprego contratado, em suas diversas variações assumidas com as mudanças nas relações de trabalho a partir do final do século XX.
} 
exigências mais elevadas de escolaridade tanto para o ingresso no mercado de trabalho, quanto para a permanência neste. Ademais, os índices de desemprego e exclusão social apontam que as populações menos escolarizadas são afetadas primeiramente, o que reforça a previsão de que as desigualdades escolares irão cada vez mais repercutir nas oportunidades de emprego disponíveis ao trabalhador, fundamentalmente entre os jovens pobres (OLIVEIRA; SOUSA, 2013).

Tal discurso tem embasado a expansão e profissionalização sem precedentes do ensino superior no Brasil, principalmente nos últimos dez anos. Segundo Rocha-de-Oliveira e Piccinini (2012a, p.64), nas últimas décadas, o país " [...] passou por transformações que redefiniram a dinâmica econômica, os modos de gestão empresarial e o mercado de trabalho". Segundo dados da Pesquisa Nacional por Amostra de Domicílios (PNAD), o tempo médio de escolaridade do brasileiro passou de 5,7 anos em 1992, para 8,8 anos em 2012 (IPEA, 2013).

Apesar de no Brasil o discurso de equivalência entre educação/qualificação profissional e emprego ainda ser predominante, fazendo com que se mantenha vivo o fetiche do poder da educação (OLIVEIRA; SOUSA, 2013), pesquisas apontam que há um número significativo de brasileiros mais escolarizados que não conseguem obter colocações correspondentes às suas qualificações (LEMOS, DUBEUX e PINTO, 2009). Além disso, Sposito (2005) acrescenta que as mudanças ocorridas nos últimos 30 anos afetaram diretamente o trabalho assalariado e consequentemente modificaram os caminhos e contornos para a entrada na vida adulta, a qual se tornou menos linear e mais complexa. A escolaridade já não se apresenta como elemento garantidor da entrada no mundo do trabalho, o que tende a ocorrer, principalmente se estiver em questão a entrada em uma vaga formal. Tal fator permite que questionemos o real papel da formação no acesso às vagas de emprego disponíveis, bem como a empregabilidade como uma responsabilidade individual; pois se a formação de ensino superior não garante o acesso direto a uma vaga de emprego formal, podem existir outros elementos relevantes para investigação no processo entre formação e mercado de trabalho.

Ademais, Pochmann (2013) destaca que a expansão das vagas e facilitação do acesso ao ensino superior que tem emergido como necessária à formação para o trabalho tem, também, gradualmente postergado o ingresso de um maior número de jovens no mercado de trabalho. Diante da ampliação no tempo de estudos os jovens, de um lado, verifica-se a elevação do nível de escolaridade, aumentando - conforme a teoria do capital humano - sua empregabilidade; de outro lado, enfrentam a ausência de garantia de emprego imediato, diante da vulnerabilidade que apresentam face à diversificação das relações de emprego (GUIMARÃES, 2013).

Assim, ao mesmo tempo em que reverbera o discurso de necessidade de qualificação da mão de obra diante das mudanças no mundo do trabalho, o desemprego juvenil tem assumido relevância cada vez maior entre os estudos acadêmicos. A passagem da escola para o mercado de trabalho é apontada por Hasenbalg (2003) como fundamental diante do processo de transição da dependência dos pais à assunção plena dos papéis sociais na vida adulta. Contudo, tal processo não ocorre de modo homogêneo, sendo que grandes variações podem ser notadas tanto nos países desenvolvidos como nos em desenvolvimento. No Brasil e em outros países latino americanos, a transição escola-trabalho possui características como o ingresso precoce na esfera laboral e a conciliação entre estudo e trabalho, que não permitem que se reflita sobre a relação qualificações educacionais e a entrada no mundo do trabalho, sem que outros elementos sociais sejam levados em conta.

Além disso, Castro e Andrade (2013) postulam que, para além das diferenças entre países, as questões que afetam a juventude são vividas de forma diversificada e desigual, variando de acordo com a origem social, a raça, o sexo, as disparidades socioeconômicas entre o campo e a cidade e, entre as regiões do Brasil. Entretanto, apesar dessa heterogeneidade, há um ponto de consenso entre os analistas: de modo geral, a inserção profissional dos jovens tem sido marcada pela precariedade e pela insegurança (GANZ LUCIO, 2013).

O aumento do tempo escolar, a postergação da entrada dos jovens no mercado de trabalho, a situação de desemprego enfrentada por possuidores de diploma de ensino superior, em suma, a alteração na forma de ingresso no mercado de trabalho não é algo totalmente novo. Países que passaram pela expansão do ensino superior em décadas anteriores, como a França, tiveram que lidar com questões semelhantes. Posto isso, o próximo tópico apresenta alguns estudos franceses de modo a lançar luz sobre questões que possam auxiliar na reflexão sobre a relação entre expansão e profissionalização do ensino superior e mercado de trabalho. 


\section{Expansão e Profissionalização do Ensino Superior: estudos franceses}

Parte-se aqui, do referencial francês, devido a quatro razões: (i) o processo de expansão e profissionalização do ensino superior estar consolidado nesse país; (ii) na França, o ingresso dos jovens no mercado de trabalho ser considerado uma preocupação política em razão das dificuldades encontradas pelos jovens para ingressar no mercado de trabalho a partir de 1970; (iii) a tradição em estudos sobre inserção profissional de jovens de grupos sociais diversos no país; (iv) a realização de diversos estudos acerca de qualificação e mercado de trabalho, inclusive com um centro especializado sobre a temática, conhecido mundialmente, o "Centro de Estudos e Pesquisas sobre Qualificações" (Céreq) (ROCHA-DE-OLIVEIRA e PICCININI, 2012a; 2012b). É relevante mencionar ainda que apesar de se lançar mão de estudos franceses para refletir acerca da realidade brasileira, não se objetiva dizer que existe um modelo a ser seguindo, mas sim, enfatizar que os estudos acerca de inserção profissional no país são recentes e que existe uma carência, principalmente de estudos que visem avançar teoricamente sobre a temática, levando em conta as especificidades do país. A busca por pesquisadores franceses se constitui como tentativa de construir um olhar alternativo ao discurso meritocrático que domina o sistema de ensino e o mercado de trabalho no Brasil, mas com a ciência das diferenças existentes tanto no que se refere ao momento de expansão do ensino superior, quanto às diferenças históricas, sociais e econômicas entre os dois países.

Na França, a expansão do ensino superior que iniciou em meados dos anos 1960, resultou no que Verley e Zilloniz (2010) entendem como segmentação do ensino superior, a qual limita a igualdade de chances no mercado de trabalho. Em resposta a uma demanda crescente por formação profissional, aumentaram vertiginosamente, até o início dos anos 2000 as instituições profissionalizantes como os STS (sections de techniniciens supérieurs) e os IUT (instituts universitaires de technologie), de sorte que somente um em cada dois estudantes frequentavam universidades. Os outros 50\% estavam matriculados nas intituladas Grandes Écoles, nos STS ou nos IUT.

Segundo os autores, tal segmentação do ensino superior foi responsável por uma fragmentação da experiência dos estudantes - a qual se liga à sua origem social e ao desempenho obtido no ensino médio - e uma segmentação dos valores dos diplomas para ter acesso aos trabalhos mais qualificados. Assim, apesar de a expansão do ensino superior ter permitido uma relativa abertura do acesso das classes populares a esse nível de ensino, a representação das origens sociais permaneceu desigual (VERLEY e ZILLONIZ, 2010). Beaud (2008) complementa que a diversificação das estruturas de ensino superior e as práticas seletivas de ingresso tendem a restringir as possibilidades reais de equalização das chances no mercado de trabalho.

Para Verley e Zilloniz (2010) a segmentação do ensino superior seria resultado tanto da expansão como um todo, quanto da criação e aumento crescente dos cursos superiores profissionais, resultando em uma segmentação hierarquizada entre os modelos de ensino superior, de modo que o processo seletivo, o caráter profissionalizante e o valor dos diplomas para acesso a trabalhos mais qualificados passaram a distinguir o "valor" dos cursos, independente da qualidade intrínseca possuída. Outra constatação dos autores foi que apesar de ter havido uma relativa abertura de acesso às classes populares, as desigualdades sociais são mantidas no acesso dos estudantes às vagas no ensino superior, o que resulta em um contexto de degradação das perspectivas de mobilidade social dos jovens.

Felouzis (2008) defendeo crescimentoda complexidade do processo de transição entre formação e entrada na vida ativa, a qual deve ser analisada como o resultado da articulação entre expansão das universidades, de um lado, e mercado de trabalho, do outro. Da crescente profissionalização da formação, iniciada na década de 1960 com os IUT até a criação dos mestrados profissionais resultou em uma modificação na missão das universidades, que não mais se limita à produção e à difusão de saber e conhecimento, mas se estende à formação profissional - à capacidade de orientação e inserção profissional.

Já Béduwé, Espinasse e Vincens (2007) entendem o aumento dos cursos superiores profissionais e a relevância que têm assumido, principalmente da década de 1990 em diante, como uma necessidade de prover os jovens de competências profissionais e capacidades de adaptação necessárias às empresas, em virtude do imperativo de fazerem face aos avanços tecnológicos cada vez mais rápidos. Assim, a preocupação dos autores é com a baixa correspondência entre a especialização adquirida na formação em CSTs e a especialidade das vagas de emprego.

Outro resultado da expansão e diversificação do ensino 
superior francês é a elevação no nível de escolaridade dos jovens. Em consonância ao que parece estar ocorrendo no Brasil atualmente, na França, apesar de o diploma ter um valor instrumental forte no mercado de trabalho (VERLEY e ZILLONIZ, 2010) e, portanto, aumentar a empregabilidade, Cohen (2007) postula que ele não é mais compreendido como garantia de emprego imediato. Ademais com o crescimento das taxas de desemprego, passou-se a notar uma tendência de diplomados assumirem, no mercado de trabalho, funções menos qualificadas do que estão aptos de acordo com sua formação déclassement.

Em complemento, Lemistre (2008), questiona as políticas educativas que querem aumentar o número de diplomados para 50\% da população até 2015, contra $42 \%$ aferidos em 2008. Para Lemistre essa "inflação" de diplomas aumentará a desvalorização dos mesmos e agravará ainda mais o caso de déclassement, o qual tenderá a se tornar durável e massivo. Cohen (2007) postula que o fenômeno do déclassement vem se acentuando nos países europeus já desde meados dos anos 1990 e tem se apresentado como um processo que atinge, principalmente, mulheres, jovens e minorias étnicas (COHEN, 2007).

O Centro de Estudos e Pesquisas sobre Qualificações (Céreq) que realiza estudos com os egressos do ensino superior na França, desde 1992 tem assinalado alguns elementos sociais estão diretamente relacionados com o nível de diploma obtido. As origens socioculturais foram apontadas como fortes condicionantes do capital escolar, entre elas, a categoria socioprofissional do pai (seu emprego) e o lugar de residência no momento dos estudos (CÉREQ, 2010). Além disso, o tipo de curso escolhido, o sexo e o fato de ser imigrante ou não também são condicionantes da inserção profissional dos jovens (CÉREQ, 2013). Segundo estudo feito em 2013, com egressos do ano de $2010,75 \%$ dos diplomados acessaram o primeiro emprego nos seis meses após terem se formado, contudo, mais de dois terços dos jovens obtiveram empregos de duração determinada. Dessa forma, o acesso rápido é acompanhado de instabilidade e precariedade (CEREQ, 2013).

Em estudo comparativo geracional Ménard (2014), confronta os egressos do ensino superior na França em 2004 e 2010. O estudo revela que a grande maioria dos egressos de 2010 estão mais expostos ao desemprego e são piores remunerados que os egressos de 2004. O trabalho aponta ainda que a especialidade de formação tem interferido muito na qualidade da inserção profissional dos jovens, de modo que os que possuem o ensino superior básico mais dois ou três anos de estudo estão mais protegidos do desemprego, seguidos pelos formados em cursos profissionais. Apesar de a taxa de desemprego dos que saem de formações profissionais curtas ser menor do que a dos com formação alongada de mestrado, por exemplo, eles recebem salários cerca de $22 \%$ menores. Quando a comparação é feita com os egressos de cursos de doutorado ou das escolas de comércio e engenharia essa diferença chega a até $47 \%$ menos. Contudo, é relevante mencionar que quando a comparação e feita com cursos que seriam equivalentes aos nossos bacharelados em ciências, ciências sociais e saúde social, a média de salário é muito semelhante (MÉNARD, 2014).

Assim, na França, em um contexto no qual há um grande número de egressos do ensino superior, Grelet (2011) aponta que o critério diploma não é mais suficiente para compreender o processo de inserção profissional. Muitas empresas avaliam, por exemplo, o percurso escolar e a acumulação de diplomas, a qual seria responsável pela ampliação de competências. Tal fator torna ainda mais preocupante o processo de segmentação do sistema de ensino, pois além de reproduzir internamente as desigualdades sociais, estas parecem repercutir no mercado de trabalho, prejudicando a mobilidade social dos jovens.

Dessa forma, Rocha-de-Oliveira e Piccinini (2012a), postulam que nesses países onde o acesso ao diploma de ensino superior deixou de ser garantia de ingresso automático no mercado de trabalho e, os números de desemprego e trabalhos precários para jovens com formação universitária passaram a se ampliar, estudos vem sendo realizados desde a década de 1980. Como forma de compreender o fenômeno e nortear políticas públicas integrando formação e trabalho, pesquisadores franceses de diferentes áreas (economia, sociologia, estatística, administração) têm realizado estudos para explorar os processos de inserção profissional dos egressos das diferentes formações (ROCHA-DE-OLIVEIRA; PICCININI, 2012a).

Apesar de os estudos realizados na França nos apontarem algumas possibilidades para conhecermos os processos de inserção profissional no Brasil é importante considerar que os mercados de trabalho existentes no país podem apresentar diferenças fundamentais para o entendimento da repercussão 
da expansão dos cursos superiores tecnológicos, além de ocorrerem em momento temporal distinto. Alguns esforços já estão sendo feitos no sentido de articular a expansão do ensino superior às mudanças ocorridas no mercado de trabalho no Brasil, a exemplo de Rochade-Oliveira e Piccinini (2012a; 2012b) que buscam entender os caminhos de inserção profissional de estudantes de administração, e de Lemos, Dubeux e Pinto (2009) que questionam, com base em Bourdieu (1988), a qualificação profissional como diferencial para inserção no mercado de trabalho. Contudo, muito ainda resta a ser feio para um maior entendimento das repercussões da expansão e especificamente da profissionalização do ensino superior para o mercado de trabalho.

Posto isso, a próxima seção busca trazer reflexões iniciais acerca do crescimento do ensino superior no Brasil e a empregabilidade dos jovens.

\section{Crescimento do Ensino Superior Profissional no Brasil e a Empregabilidade dos Jovens}

No Brasil, o ensino superior só passou a adquirir cunho universitário na década de 1930. De acordo com Marques e Cepêda (2012), o modelo de sistema universitário que se desenvolveu no país até meados da década de 1990, foi um misto de acesso restrito e excludente - concentrado principalmente em eixos metropolitanos e próximos aos polos econômicos - com uma drástica expansão do ensino superior privado, impulsionado pelo aumento da demanda por vagas e pela capacidade reduzida das instituições públicas de responderem a essa demanda.

Com as mudanças em âmbito global, resultantes dos ajustes estruturais neoliberais, bem como com a redemocratização do país no final da década de 1980 e a promulgação da Constituição Federal de 1988 que tornou a educação um direito social inalienável
-, a educação passou a ocupar um papel de destaque no âmbito das ações do Estado (GUIMARÃES DOS SANTOS, 2013) e também na esfera da iniciativa privada, que passou a ver na educação uma oportunidade de lucro (BALL, 2004). Desde o final da década de 1990 começou a se notar uma expansão tanto no número de instituições como no número de matrículas no ensino superior. Contudo, é a partir do novo milênio que tem início uma expansão e diversificação sem precedentes do ensino superior no Brasil, a qual apresenta quatro pontos relevantes.

O primeiro deles é o aumento no número de matrículas totais em ensino superior: o Censo de 2015 registrou um total de 8.027.297 matrículas, contra um pouco mais de 3 milhões registradas em 2001 (BRASIL, 2012; INEP, 2015). O segundo ponto é o aumento do número de matrículas em instituições privadas, que desde o final da década de 1990, têm apresentado um crescimento significativamente maior que em instituições públicas, atingindo a marca de $75,7 \%$ do total das matrículas em ensino superior no ano de 2015. Em terceiro lugar, a inserção da modalidade de ensino à distância, que foi criada em 2001 e passou, desde então, a crescer regularmente, atingindo em 2015, 17,4\% do total de matrículas no ensino superior. Por fim, o quarto ponto é a diversificação pela qual tem passado o ensino superior, com a inserção de cursos superiores tecnológicos (CSTs), cujo foco passa a ser a qualificação dos trabalhadores, de modo que possam contribuir com a inserção das organizações na economia global (BRASIL, 2001, INEP, 2015).

A expansão e diversificação do ensino superior dos últimos 15 anos, em especial, pode ser creditada a diversas causas, a saber: a reforma da educação iniciada com a Lei de Diretrizes e Bases da Educação Nacional (LDB/96); a universalização do ensino básico, que criou uma nova demanda pelo ensino superior; o crescimento de políticas públicas e programas de educação voltados para esse nível - o ProUni ${ }^{6}$, Reuni ${ }^{7}$, Fies $^{8}$, entre outros -, a demanda das empresas por maior qualificação da mão de

\footnotetext{
${ }^{6}$ O Programa Universidade para Todos é uma iniciativa “do Ministério da Educação, criado pelo Governo Federal em 2004, que concede bolsas de estudo integrais e parciais $(50 \%)$ em instituições privadas de ensino superior, em cursos de graduação e sequenciais de formação específica, a estudantes brasileiros, sem diploma de nível superior” (BRASIL, 2014b).

7 O Programa de Apoio a Planos de Reestruturação e Expansão das Universidades Federais (Reuni): iniciado em 2003, com o objetivo principal de ampliar o acesso e a permanência na educação superior. Entre 2003 e 2011 o número de municípios atendidos por universidades federais passou de 114 para 237, além disso, foram criadas 14 novas universidades e mais de 100 novos campi que possibilitaram a ampliação de vagas e a criação de novos cursos de graduação (BRASIL, 2014c).

8 "O Fundo de Financiamento Estudantil (Fies) é um programa do Ministério da Educação destinado a financiar prioritariamente estudantes de cursos de graduação”, que ingressam em instituições privadas (BRASIL, 2014d).
} 
obra frente às novas tecnologias e ao novo ciclo da globalização, etc. Para além da preocupação com a equação quantidade/qualidade que acompanha a expansão do ensino superior no Brasil e permeia diversos estudos (GRAMANI, 2008; REAL, 2009; TAVARES; OLIVEIRA; SEIFFERT, 2011; CUNHA, 2014), a diversificação dos cursos oferecidos e dos estudantes que entram no ensino superior têm se tornado questões relevantes (SMANIOTTO; MERCURI, 2007).

Conforme suprarreferido, os cursos superiores profissionais no Brasil datam da década de 1960 (BRASIL, 1968). Para Takahashi (2010) os CSTs começaram a ser ofertados no contexto de industrialização e modernização promovido no país em meados do século XX, mediante a necessidade de formar e qualificar trabalhadores para atender à demanda das empresas que se instalavam. Durante a década de 1970 houve grande incentivo à ampliação dos CSTs, sendo que as primeiras experiências foram de instituições privadas. Em 1974 foi inaugurado o curso de Engenharia de Operação nas áreas de Construção Civil, Elétrica e Eletrônica no Cefet-PR (SMANIOTTO; MERCURI, 2007). Entretanto, a essa época a educação profissional superior permaneceu atrelada à formação de classes menos favorecidas, absorvendo o preconceito nutrido pelas elites em relação à educação profissional de nível médio (TAKAHASHI, 2010).

No final da década de 1970, diante da pressão exercida pelo Conselho Regional de Engenharia e Arquitetura (Crea), que não reconhecia e limitava a atuação dos tecnólogos de engenharia, a procura diminuiu até que esses e outros cursos de curta duração foram abandonados pelo Ministério da Educação (MEC). Outras iniciativas surgiram na década de 1980, mas até o final da dos anos 1990, os CSTs tiveram um crescimento modesto (SMANIOTTO; MERCURI, 2007).

Apesar de em 1994, a Lei nº 8.948 ter instituído o Sistema Nacional de Educação Tecnológica, é somente a partir de 1996, com a Lei n $9.394 / 96$ e o Decreto Federal n ${ }^{\circ}$ 2.208/97 que o ensino tecnológico começa a ganhar nova dimensão na educação superior brasileira (BRASIL, 1994; BRASIL, 1996; BRASIL, 1997). Em 1999, os Centros de Educação Tecnológica e Faculdades de Tecnologia ofereciam apenas 74 cursos em todo o país, os quais eram exclusividade do setor público federal e estadual. Tal situação viria a se alterar em 2001, com as mudanças no ensino superior resultantes da Lei $\mathrm{n}^{\circ}$ 9.934/96 e com a entrada novamente do setor privado na oferta de cursos inicialmente com 30 cursos. Em 2004, o número total de CSTs oferecidos já havia saltado para 758 - desses, 390 eram de instituições privadas (INEP, 2004).

De acordo com Campello et al. (2009) a expansão dos cursos superiores tecnológicos que passou a ser registrada a partir de 2001 tem como base as reformas educativas do Brasil que começaram a ser implantadas nos governos de Fernando Henrique Cardoso e Luiz Inácio Lula da Silva, do final da década de 1990 em diante. O Decreto $n^{\circ} 2.208$ de 17 de abril de 1997, que altera a Lei de 1996 , em seu artigo $10^{\circ}$, determina que os CSTs são cursos de nível superior, que correspondem à educação profissional de nível tecnológico e deverão focar sua estruturação de modo a "[...] atender aos diversos setores da economia, abrangendo áreas especializadas, e conferirão diploma de Tecnólogo" (BRASIL, 1997, s/p). Assim, os cursos superiores de tecnologia que haviam sido criados em 1970 passam por reformulações com vistas à ampliação do ensino superior e a atender a demanda do sistema produtivo (TAKAHASHI, 2010).

Em 2008 com a Lei $n^{\circ} 11.892 / 08$, que instituiu a Rede Federal de Educação Profissional, Científica e Tecnológica e criou os Institutos Federais de Educação, Ciência e Tecnologia, o ensino tecnológico iniciou uma expansão sem precedentes na história do país. Muitos Centros Federais de Educação Profissional e Tecnológica (Cefets) foram transformados em Institutos Federais e habilitados a oferecerem cursos de nível superior, outros tantos foram abertos em diversos pontos do país. Atualmente existem 562 escolas em atividade, destas 38 são Institutos Federais (BRASIL, 2014a).

Paralelamente aumentou também o número de cursos e matrículas na rede privada, fator que podemos atribuir, pelo menos em parte, às políticas públicas de incentivo ao acesso aos cursos superiores nas redes privadas como ProUni ${ }^{9}$ e Fies ${ }^{10}$, juntamente com a valorização do ensino superior profissional

\footnotetext{
${ }^{9}$ Programa Universidade para Todos.

${ }^{10}$ Fundo de Financiamento Estudantil.
} 
suprarreferida. O número de matrículas em instituições privadas passou de $448.405 \mathrm{em} 2008$, para $887.478 \mathrm{em}$ 2014, ou seja, praticamente dobrou (INEP, 2014).

Tal expansão do ensino superior profissional, tanto público como privado, contribuiu para aumentar o acesso às instituições de ensino superior, pois além de aumentar a oferta de vagas, iniciou uma deslocalização desse nível de ensino, o qual historicamente estava atrelado aos grandes centros urbanos. O catálogo de cursos superiores de tecnologia de 2016, que atualiza o de 2010, conta com 134 denominações de cursos 21 a mais que em 2010, que se dividem em 13 áreas, a saber: ambiente e saúde (9), controle e processos industriais (14), desenvolvimento educacional e social (1), gestão e negócios (13), informação e comunicação (14), infraestrutura (12), militar (11), produção alimentícia (7), produção cultural e design (14), produção industrial (14), recursos naturais (14), segurança (6), e turismo, hospitalidade e lazer (5) (BRASIL, 2016).

Segundo Takahashi (2010), o novo foco passou a ser a qualificação dos trabalhadores, de modo que possam contribuir com a inserção das organizações na economia globalizada. A autora, com base no parecer CNE/CES n ${ }^{\circ}$ 436/2001, aponta que os cursos superiores tecnológicos foram criados para "[...] atender a uma demanda do mercado por especialistas dentro de uma área de conhecimento e estão orientados por características como foco, rapidez e flexibilidade, enquanto as outras modalidades de ensino superior visam formar generalistas" (TAKAHASHI, 2010, p. 389).

Assim, esse tipo de formação pode tanto estar destinado a atender demandas locais do mercado de trabalho, vinculando a área de estudo com a vaga a ser ocupada, quanto formando jovens que terão uma atuação restrita nesse mercado. Formar jovens especialistas, com foco, que atendam a necessidades específicas é interessante para as empresas e pode ser a oportunidade de acesso a uma vaga formal no mercado de trabalho, mas também, pode significar que esse mercado quando atingir um nível de saturação vá redirecionar esses jovens para vagas abaixo de sua formação, o déclassement percebido na França, ou para vagas que não tenham ligação com a especialidade que estudaram. Nesses dois casos, a formação não estaria contribuindo para a empregabilidade dos jovens, ou pelo menos, não estaria os levando a ocuparem uma vaga qualificada de trabalho. Por isso, entende-se que são de suma importância estudos empíricos que revelem que vagas estão ocupando os egressos de CSTs nas diferentes áreas de formação. Dessa forma, apesar de neste trabalho entender-se que a expansão e profissionalização do ensino superior possam permitir uma relativa abertura do acesso das classes populares a esse nível de ensino, em paralelo ao que ocorreu na França, é possível que nos próximos anos se perceba a permanência da desigualdade da representação das origens sociais e a não contribuição da formação de nível superior para a mobilidade social desses jovens.

Outro ponto que merece atenção é a segmentação dos diplomas. É preciso que se pesquise se os CSTs são cursos mais focados e procurados por estudantes que querem acessar uma vaga deste tipo no mercado de trabalho, ou se por serem cursos mais rápidos e muitas vezes mais baratos, não estão servindo para atender a uma demanda reprimida das classes populares brasileiras, que provavelmente não teriam acesso a esse nível de ensino e, portanto, sendo responsável por uma fragmentação das experiências dos estudantes, a qual, assim, como na França, estaria ligada à origem social destes e ao desempenho no ensino médio.

Também precisa seranalisado o papel das universidades, que em países como a França, por exemplo, não está ligado somente ao ensino/conhecimento, mas também à inserção dos jovens egressos. Na França, as próprias universidades possuem a preocupação de verificar onde estão seus egressos, que vagas eles estão ocupando. A Universidade de Lyon, por exemplo, possui um centro de estudos sobre trabalho ${ }^{11}$, o mesmo ocorre com a Sorbonne ${ }^{12}$, com a Universidade ParisDauphine $^{13}$, com a Universidade de Toulouse ${ }^{14}$, entre outras. O Governo Francês possui um Ministério dedicado à educação nacional, ao ensino superior e à pesquisa ${ }^{15}$, que se preocupa com a inserção profissional dos jovens e realiza pesquisas acerca da temática. Além, claro, do já mencionado Centro de Estudos e Pesquisas sobre Qualificações, Céreq.

\footnotetext{
${ }^{11}$ http:/ /ietl.univ-lyon2.fr/.

${ }^{12}$ https://www.univ-paris1.fr/services/orive/

${ }^{13} \mathrm{http}: / /$ www.dauphine.fr/fr/formations-et-diplomes/orientation-insertion.html.

${ }^{14} \mathrm{ttp}$ ://www.ut-capitole.fr/orientation-et-insertion/etudes-sur-les-parcours-et-l-insertion-professionnelle-des-etudiants/etudes-surles-parcours-et-l-insertion-professionnelle-des-etudiants-321582.kjsp.

${ }^{15}$ http:/ / www.enseignementsup-recherche.gouv.fr/pid24748/evaluation-statistiques.html.
} 
No Brasil, esta preocupação ainda é incipiente. Existem alguns projetos de pesquisa como o realizado em parceria com a Universidade Federal do Rio Grande do Sul e a PUC-RJ, mas que se focam somente nos cursos de Administração das respectivas universidades. O Governo Federal ainda não possui programas ou projetos que visem acompanhar a inserção profissional dos jovens, e muito menos especificamente dos egressos de CSTs (VOLKMER MARTINS; ROCHA-DE-OLIVEIRA, 2014). Faltam levantamentos estatísticos e estudos qualitativos no Brasil que permitam entender a relação entre formação profissional de nível superior e inserção profissional. Assim, apesar de a expansão e a profissionalização do ensino superior serem fenômenos recentes, é importante que não sejam negligenciados, sobretudo em um cenário mundial marcado pelo desemprego e precariedade do trabalho juvenil.

Outro ponto que merece dedicação é a diferença existente entre as diversas áreas de formação. É interessante pesquisar, por exemplo, em cursos como os da área de gestão, qual diferença entre as vagas ocupadas pelos bacharéis em Administração e os formados em cursos superiores de Gestão de Negócios. Entender se há uma diferença dos valores dos diplomas para ter acesso aos trabalhos mais qualificados, independente da qualidade do curso em si. Ou então, compreender como funciona o mercado de trabalho para os egressos de cursos ligados à área da informática, a qual é historicamente uma área carente em mão de obra no Brasil. Ou ainda, como os egressos dos cursos ligados à economia criativa, como moda, design, gastronomia, jogos eletrônicos e mídias digitais tem se inserido.

Por fim, quando se leva em conta a expansão e profissionalização do ensino superior no Brasil, é necessário refletir se de fato o aumento do número de matrículas e de egressos tem resultado em maior inserção profissional. E quando se fala em inserção profissional, a preocupação não se volta apenas para a entrada no mercado de trabalho, mas também considera a qualidade das vagas que os jovens estão ocupando. Com a flexibilização das relações de trabalhos, muitas vezes a entrada no mercado de trabalho se dá por meio de vagas de emprego precárias, informais, com salários baixos, contratos por tempo determinado. Analisar se isto está ocorrendo com os egressos de CSTs e, também quais elementos que além da formação podem estar interferindo no processo de inserção, pode ajudar a clarear sobremaneira esse processo que é a transição entre a formação e a entrada no mercado de trabalho.

\section{Considerações Finais}

O presente artigo objetivou discutir a relação entre o crescimento do ensino superior profissional no Brasil e a empregabilidade dos jovens egressos de cursos superiores de tecnologia. Para tanto, mobilizou estudos franceses sobre a temática, como forma de apresentar possíveis caminhos que essa relação entre formação profissional de nível superior e mercado de trabalho pode seguir nos próximos anos no Brasil. Contudo, apesar de os estudos franceses apontarem algumas direções, é necessário fazer a ressalva de que vivemos em condições sociais, culturais e econômicas diversas, além de a nossa expansão e profissionalização do ensino superior serem posteriores, o que torna necessário aprofundar os estudos tanto empíricos como teóricos que levem em conta a nossa realidade e também diversidade nacional.

Além disso, refletir acerca da relação entre expansão do ensino superior profissional e a empregabilidade dos jovens buscou também chamar a atenção para a necessidade de uma maior articulação entre os programas de expansão do ensino superior e as políticas públicas voltadas para a inserção profissional dos jovens no Brasil, conforme apontam Volkmer Martins e Rocha-de-Oliveira (2014). A partir do momento que se criam políticas para expandir o acesso ao ensino superior e, especificamente, ampliar as vagas de formação profissional, aumenta-se a demanda por empregos qualificados, contudo, sem que se perceba por parte do Governo Federal a preocupação com a criação de políticas públicas destinadas à inserção profissional desses egressos. A importância de aprofundar estudos sobre a temática tem como finalidade tanto a produção de dados como teorias que reflitam a realidade nacional e sejam capazes de dar conta da relação entre formação e entrada do mercado de trabalho, com vistas a contribuir para a elaboração de políticas públicas que articulem o sistema de ensino superior e o mercado de trabalho.

Ademais, estudos sobre a temática são relevantes, pois a partir do momento que se amplia o acesso ao ensino superior ao mesmo tempo em que se cria uma hierarquização entre os cursos, pode-se questionar a capacidade desse nível de ensino de aumentar a igualdade no acesso às vagas disponíveis 
no mercado de trabalho. Nesse caso, a manutenção das desigualdades sociais no acesso dos estudantes às vagas no ensino superior e possivelmente às vagas no mercado de trabalho, resultaria na degradação das chances de mobilidade social e abalaria o papel da formação profissional na empregabilidade desses jovens. Tal fator resultaria ainda no questionamento da visão de empregabilidade como responsabilidade do indivíduo, pois a partir do momento que podem existir outros elementos capazes de interferir na inserção profissional, a responsabilização única do indivíduo perde a força.

Assim, este trabalho não tem pretensão de encerrar a discussão, mas sim de apresentar possibilidades e incitar a discussão necessária sobre os CSTs no Brasil: quem são seus alunos, quais vagas de emprego ocupam seus egressos, quais suas particularidades entre áreas, e mesmo em relação aos cursos superiores de bacharelado. Estudos empíricos podem ajudar a levantar dados para que entendamos esse processo, mas é importante que não sejam apenas pontuais e que fomentem a sistematização de dados que possam auxiliar na construção de políticas públicas que vinculem formação profissional de ensino superior e inserção profissional. Quando o ensino, em especial o ensino superior, é tido como estratégia de transformação social, devido sua capacidade de impulsionar o desenvolvimento tecnológico, aumentar a capacidade crítica da população e contribuir para mobilidade social geracional (RIBEIRO, 2011; 2012; GUIMARÃES DOS SANTOS, 2013) é essencial que pesquisas sejam realizadas nesse âmbito. Quando a educação, conforme afirma Ribeiro (2012), é entendida como o principal mecanismo de mobilidade social, compreender se os CSTs oferecem essa oportunidade ou são somente para atender uma demanda sazonal e específica do sistema produtivo é fundamental para estudos de desigualdade e exclusão social.

Com vistas a contribuir para o avanço desse campo de estudos, este artigo propõe algumas possibilidades de pesquisa:

a) Entender como ocorre o processo de inserção profissional dos estudantes e egressos de cursos superiores tecnológicos;

b) Compreender o papel das IES diante dessa nova conjuntura relacional entre ensino superior profissional e mercado de trabalho no Brasil;

c) Analisar semelhanças e diferenças no processo de inserção de bacharéis e tecnólogos na mesma área de conhecimento;

d) Analisar o impacto do crescimento de cursos superiores profissionais para o mercado de trabalho brasileiro;

e) Analisar se o aumento dos investimentos em formação profissional de nível superior tem aumentado a empregabilidade dos jovens;

f) Analisar como as empresas percebem os egressos dos cursos superiores profissionais e como pensam suas carreiras nas organizações;

g) Analisar se a formação profissional de nível superior é capaz de eliminar diferenças como a origem econômico-social no momento da inserção profissional;

h) Analisar quais elementos sociais, além da formação superior profissional podem influenciar a entrada dos jovens no mercado de trabalho.

Em suma, existem diversas questões sem resposta. Este ensaio buscou trazer sugestões que estimulem pesquisadores na busca por uma maior teorização sobre o tema com vistas a contribuir para a demanda social criada em torno da problemática da expansão do ensino superior profissional no Brasil e sua relação com a empregabilidade dos jovens. Julga-se que essa relação seja de fundamental importância, e que trabalhos empíricos podem contribuir, futuramente, com dados para embasar políticas públicas que articulem o ensino superior profissional e o mercado de trabalho.

\section{Referências}

ALMEIDA JUNIOR, Eurico Pedroso de; PILATTI, Luiz Alberto. Empregabilidade do Profissional Formado nos Cursos Superiores de Tecnologia do CEFET-PR: estudo de caso em médias e grandes empresas da região norte do Paraná. Ensaio:

Avaliação de Políticas Públicas educacionais, Rio de Janeiro, v. 15, n. 56, p. 429-446, jul./set/, 2007.

BALL, S. J. Performatividade, Privatização e o PósEstado do Bem-Estar. In: Educação e Sociedade. Campinas, v. 25, n. 89, set./dez. 2004, p. 1105-1126. Disponível em: <http://www.scielo.br/pdf/es/ v25n89/22613.pdf>. Acesso em: 18 fev. 2010. 
BEAUD, Stéphane. Enseignement supérieur: la " démocratisation scolaire » en panne. 2008) Formation emploi, n. 101, jan./mar., 2008, p. 149-165.

BÉDUWÉ, Catherine; ESPINASSE, Jean-Michel; VINCENS, Jean. De la formation professionnelle à La professionnalité d'une formation. Revue Française de Sciences Sociales: Formation Emploi, n. 99, juillet-septembre 2007, p. 103-121.

BOURDIEU, Pierre. A distinção: crítica social do julgamento. 2. Ed. Porto Alegre: Zouk, 2015.

BRANDÃO, Marisa. Cursos Superiores de Tecnologia: democratização do acesso ao ensino superior? 29ª Reunião Anual da ANPEd, 15 a 18 outubro, Caxambu, MG, 2006. Disponível em: <http:/ /29reuniao.anped.org.br/trabalhos/trabalho/ GT09-2018--Int.pdf>. Acesso em: 02 jul. 2014.

BRASIL. Planalto. Presidência da República. Lei $n^{\circ}$ 5.540/68, de 28 de novembro de 1968. Fixa normas de organização e funcionamento do ensino superior e sua articulação com a escola média, e dá outras providências. Disponível em: < http://www.planalto. gov.br/ccivil_03/leis/15540.htm>. Acesso em 01 jul. 2014.

BRASIL. Planalto. Presidência da República. Lei $n^{\circ}$ 8.948/94, de 08 de dezembro de 1994. Dispõe sobre a instituição do Sistema Nacional de Educação Tecnológica e dá outras providências. Disponível em: <http://www.planalto.gov.br/ccivil_03/leis/L8948. htm>. Acesso em: 05 jul. 2014.

BRASIL. Planalto. Presidência da República. Lei n ${ }^{\circ}$ 9.934/96, de 20 de dezembro de 1996. Estabelece as diretrizes e bases da educação nacional. Disponível em: <http://www.planalto.gov.br/ccivil_03/leis/ L9934.htm>. Acesso em: 01 jul. 2014.

BRASIL. Planalto. Presidência da República. Decreto de Lei $\mathrm{n}^{\circ}$ 2.208, de 17 de abril de 1997. Regulamenta o $\int 2^{\circ}$ do art. 36 e os arts. 39 a 42 da Lei n ${ }^{\circ} 9.394$, de 20 de dezembro de 1996, que estabelece as diretrizes e bases da educação nacional. Disponível em: <http:/ / www.planalto.gov.br/ccivil_03/decreto/D2208.htm>. Acesso em: 01 jul. 2014.

BRASIL. Ministério da Educação. Conselho Nacional de Educação. Portal do MEC. Parecer $\mathrm{CNE} / \mathrm{CES} n^{\circ}$ 436, de 02 de abril de 2001. Disponível em: <http://portal.mec.gov.br/cne/arquivos/pdf/ CES0436.pdf $>$ Acesso em 02 jul. 2014.
BRASIL. Ministério da Educação. Censo da Educação Superior 2012. Disponível em: < http:/ / download.inep.gov.br/educacao_basica/censo_ escolar/resumos_tecnicos/apresentacao_coletiva_ censo_superior_2012.pdf>. Acesso em: 16 jul. 2014.

\section{BRASIL. Ministério da Educação.}

Catálogo Nacional de Cursos Superiores de Tecnologia - 2016. Disponível em: < http:/ / portal.mec.gov.br/index.php?option $=$ com_ docman\&view $=$ download $\&$ alias $=44501$ - cncst 2016-3edc-pdf\&category_slug=junho-2016pdf\&Itemid=30192>. Acesso em: 15 jul. 2016.

BRASIL. Ministério da Educação. Expansão da Rede Federal de Educação Profissional, Científica e Tecnológica. 2014a. Disponível em: < http:// redefederal.mec.gov.br/>. Acesso em: 28 fev. 2016.

BRASIL. Ministério da Educação. ProUni. Apresentação. Disponível em: <http:// portal.mec.gov.br/index.php?option $=$ com_ content\&view $=$ article\&id $=205 \&$ ativo $=299 \&$ Itemid=298 > . Acesso em: 05 ago. 2014b.

BRASIL. Ministério da Educação. Programa de Apoio a Planos de Reestruturação e Expansão das Universidades Federais: Reuni. Disponível em: <http://portal.mec.gov.br/index. php?option $=$ com_content\&view $=$ article\&id $=12261$ \&ativo $=503 \&$ Itemid $=502>$. Acesso em: 05 ago. 2014c.

\section{BRASIL. Ministério da Educação. FIES.}

Apresentação. Disponível em: < http://portal. mec.gov.br/index.php?option $=$ com_content\&vie $\mathrm{w}=$ article\&id $=198$ :apresentacao\&catid $=141$ :fiesfinanciamento-estudantil\&Itemid=303 > . Acesso em: 05 ago. 2014 d.

CAMPELLO et. al. O Ensino como negócio: a expansão da oferta dos cursos de formação de tecnólogos em saúde no Brasil. Trabalho, Educação e Saúde, Rio de Janeiro, v. 7, suplemento, p. 175-190, 2009.

CASTRO, Jorge Abrahão de; ANDRADE, Carla Coelho de. Juventude, Educação e Trabalho: avanços e desafios. In: MACAMBIRA, Júnior; ANDRADE, Francisca Rejane B. Trabalho e Formação

Profissional: juventudes em transição. Fortaleza: IDT, UECE, BNB, 2013, p. 155-168.

CATTANI, Antonio David. Teoria do Capital Humano. In: CATTANI, Antonio David; HOLZMANN, Lorena (Orgs.). Dicionário de 
Trabalho e Tecnologia. Porto Alegre, RS: Zouk, 2011, p. 74-78.

CEREQ. Évaluation et données longitudinales: quelles relations? XVIIes journées d'étude sur les données longitudinales dans l'analyse du marché du travail. Marseille, 27-28 mai 2010.

CEREQ. Quand l'école est finie: premiers pas dans la vie active de la génération 2010. Enquête 2013. Marseille: Céreq, 2014.

CIAVATTA, Maria. Os Centros Federais de Educação Tecnológica e o Ensino Superior: duas lógicas em confronto. Revista de Educação Social, Campinas, vol. 27, n. 96, Especial, p. 911-934, out. 2006.

COHEN, Daniel. Introduction. In: COHEN, Daniel. Une Jeunesse Difficille: portrait économique et social de la jeunesse française. CEPREMAP: Centre pour la Recherche Économique et ses Applications. Editions: Rue d'Ulm/ Presses de l'École normale supérieure, 2007, p. 13-22.

CORAIOLA, Diego Maganhotto; BARATTER, Marystela Assis; TAKAHASHI, Adriana Roseli Wünsch. A Institucionalização dos Cursos Superiores de Tecnologia (CST's) da OPET: a adoção pioneira e a recursividade do processo. Revista de Administração da UNIMEP. São Paulo: v.11, n.1, Janeiro/Abril, p. 104-133, 2013.

CUNHA, Maria Isabel da. A qualidade e ensino de graduação e o complexo exercício de propor indicadores: é possível obter avanços?. Avaliação (Campinas) [online]. 2014, vol.19, n.2, p. 453-462. Disponível em: < http://www.scielo.br/pdf/aval/ v19n2/a11v19n2.pdf>. Acesso em: 10 set. 2014.

FELOUZIS, Georges. Des mondes incertains: les universités, les diplômés et l'emploi. Formation emploi, n. 101, jan./mar., 2008, p. 135-147.

FERREIRA, Francisco. Os determinantes da desigualdade de renda no Brasil: luta de classes ou heterogeneidade educacional? Rio de Janeiro: PUCRio, 2000. (Texto para Discussão, n.415).

FRIGOT'TO, Gaudêncio. Educação, Crise do Trabalho Assalariado e do Desenvolvimento. In: FRIGOTTO, Gaudêncio (Org.). Educação e Crise do Trabalho: perspectivas de final de século. Petrópolis, RJ: Vozes, 2011, p. 25-54.

GALLAND, O. Adolescence, post-adolescence, jeunesse: retour sur quelques interprétations. In: Revue Française de Sociologie, v. 42, n. 4, p. 611-640, 2001.

GANZ LUCIO, Clemente. Apresentação. In: MACAMBIRA, Júnior; ANDRADE, Francisca Rejane B. Trabalho e Formação Profissional: juventudes em transição. Fortaleza: IDT, UECE, BNB, 2013, p. 7-11.

GARIBA JÚNIOR, Maurício. Um Modelo de Avaliação de Cursos Superiores de Tecnologia Baseado na Ferramenta Benchmarking. 2005. 304 f. Tese (Doutorado em Engenharia de Produção) - Programa de Pós-Graduação Engenharia de Produção, Universidade Federal de Santa Catarina, Florianópolis, 2005.

GENTILI, Pablo. Educar para o Desemprego: a desintegração da promessa integradora. In: FRIGOTTO, Gaudêncio (Org.). Educação e Crise do Trabalho: perspectivas de final de século. Petrópolis, RJ: Vozes, 2011, p. 76-92.

GRAMANI, Maria Cristina N.. A influência da qualidade na atratividade de instituições de ensino superior com capital aberto. Ensaio: aval. pol.públ.Educ. [online]. 2008, vol.16, n.60, p. 437 454. Disponível em: < http://www.scielo.br/pdf/ ensaio/v16n60/v16n60a07.pdf>. Acesso em: 10 ago. 2014.

GUIMARÃES, Nadya Araujo. Trajetórias Juvenis: um novo nicho em meio à expansão das oportunidades de trabalho? In: MACAMBIRA, Júnior; ANDRADE, Francisca Rejane B. Trabalho e Formação Profissional: juventudes em transição. Fortaleza: IDT, UECE, BNB, 2013, p. 57-72.

GUIMARÃES DOS SANTOS, Geórgia Patrícia. Juventude, Trabalho e educação: uma agenda pública recente e necessária. Por quê? In: MACAMBIRA, Júnior; ANDRADE, Francisca Rejane B. Trabalho e Formação Profissional: juventudes em transição. Fortaleza: IDT, UECE, BNB, 2013, p. 73-88.

HASENBALG, Carlos. Introdução. In: HASENBALG, Carlos; VALLE SILVA, Nelson do (Orgs.). Origens e Destinos: desigualdades sociais ao longo da vida. Rio de Janeiro: Topbooks, 2003, p. 9-35.

INSTITUTO BRASILEIRO DE GEOGRAFIA E ESTATÍSTICA. IBGE. Pesquisa Mensal de Emprego (PME). Disponível em: < http:/ / www.ibge.gov.br/home/estatistica/indicadores/ 
trabalhoerendimento/pme/pmemet2.shtm>. Acesso em: 10 jan. 2016.

\section{INSTITUTO NACIONAL DE ESTUDOS E PESQUISAS EDUCACIONAIS ANÍSIO} TEIXEIRA. INEP. (2004). Resumo Técnico Senso 2004. Disponível em: <http://download.inep. gov.br/download/superior/2004/censosuperior/ Resumo_tecnico-Censo_2004.pdf>. Acesso em: 27 jun. 2014.

\section{INSTITUTO NACIONAL DE ESTUDOS E PESQUISAS EDUCACIONAIS ANÍSIO} TEIXEIRA. INEP. Sinopses Estatísticas da Educação Superior - Graduação (2014). Disponível em: <http://portal.inep.gov.br/superiorcensosuperior-sinopse>. Acesso em 24 fev. 2016.

INSTITUTO NACIONAL DE ESTUDOS E PESQUISAS EDUCACIONAIS ANÍSIO TEIXEIRA. INEP. Sinopses Estatísticas da Educação Superior - Graduação. 2015. Disponível em: <http://portal.inep.gov.br/web/guest/sinopsesestatisticas-da-educacao-superior $>$. Acesso em: 16 jan. 2016.

\section{INSTITUTO DE PESQUISA ECONÔMICA} APLICADA. IPEA. (2013). PNAD

mostra aumento da escolaridade média do brasileiro. Disponível em: <http:/ /www. ipea.gov.br/portal/index.php?option $=\mathrm{com}_{-}$ content\&view $=$ article\&id $=20012>$. Acesso em: 14 ago. 2014.

LEMISTRE, Philippe. Introdução. In: BÉDUWÉ, Catherine et. al. (éditeurs). Les nouvelles ségrégations scolaires et professionnelles. CEREQ: RELIEF n. 34. XVIII's journées d'étude sur les données longitudinales dans l'analyse du marché du travail. Toulouse, 19-20 mai. 2011, $\mathrm{s} / \mathrm{p}$.

LEMOS, Ana Heloisa da Costa; DUBEUX, Veranise Jacubowski Correia; PINTO, Mario Couto Soares. Educação, empregabilidade e mobilidade social: convergências e divergências. Cadernos EBAPE. BR, v. 7, n. 2, artigo 8, Rio de Janeiro, Jun. 2009, p. 368-384.

LEMOS, Ana Heloisa da Costa; RODRIGUEZ, Daniel Arbaiza; MONTEIRO, Vinícius de Carvalho. Empregabilidade e Sociedade Disciplinar: Uma Análise do Discurso do Trabalho Contemporâneo à Luz de Categorias Foucaultianas - Revista O\&S. vol. 18, n.59, out./dez. 2011, p.587-604.
MARQUES, Antonio Carlos Henriques; CEPÊDA, Vera Alves. Um Perfil Sobre a Expansão do Ensino Superior Recente no Brasil: aspectos democráticos e inclusivos. Perspectivas, São Paulo, v. 42, jul./dez. 2012, p. p. 161-192.

MÉNARD, Boris. Sortants du supérieur: la hausse du niveau de formation n'empeche pas celle du chômage. Céreq, BREF n. 322, setembro, 2014, p. 1-4.

NÁDER, Fernanda Milne-Jones; OLIVEIRA, Lucia Barbosa. Empregabilidade: Uma Análise Histórica e Crítica. In: Anais do XXXI EnANPAD. Rio de Janeiro: EnANPAD, 2007, p. 1-15.

NETO, Antonio C. de A.; MODESTO, Maria A. da S.; ARGOLLO, Rivailda S. N. de. Curso Superior de Tecnologia: trajetória, controvérsias e voz dos alunos de uma IES. XXIV Simpósio da Associação Nacional de Política e Administração da Educação. ANAPAE, 2009. Disponível em: < http:/ / www. anpae.org.br/congressos_antigos/simposio2009/42. pdf>. Acesso em: 13 mai. 2014.

OLIVEIRA, Elenilce Gomes de; SOUSA, Antônia de Abreu. Trabalho, Juventude e Educação no Contexto do Capitalismo Atual. In: MACAMBIRA, Júnior; ANDRADE, Francisca Rejane B. Trabalho e Formação Profissional: juventudes em transição. Fortaleza: IDT, UECE, BNB, 2013, p. 91-104.

PESQUISA NACIONAL AMOSTRA DE

DOMICÍLIOS. PNAD. Síntese de indicadores 2015 (2015). Disponível em: < http://www.ibge.gov.br/ home/estatistica/populacao/trabalhoerendimento/ pnad2015/sintese_defaultxls.shtm > . Acesso em 20 nov. 2016.

\section{PEUGNY, Camille. O destino vem do berço?}

Desigualdades e reprodução social. Campinas, SP: Papirus, 2014.

PIRES, Luciene Lima de Assis. A Expansão dos Cursos de Tecnologia e a Criação de Universidades Tecnológicas no Brasil. V Simpósio de Educação do Sudoeste Goiano. Jataí, 06 a 11 nov., 2006.

POCHMANN, Marcio. Nova Classe Média? O trabalho na base da pirâmide social brasileira. São Paulo: Boitempo, 2012.

POCHMANN, Marcio. Juventudes na Transição para a Sociedade Pós-Industrial. In: MACAMBIRA, Júnior; ANDRADE, Francisca Rejane B. Trabalho e Formação Profissional: 
juventudes em transição. Fortaleza: IDT, UECE, BNB, 2013, p. 37-55.

POCHMANN, Marcio. Políticas de Ajuste

Econômico e Desemprego no Brasil Metropolitano nos Últimos 35 Anos. In: Mercado de trabalho: qualificação, emprego e políticas sociais.

MACAMBIRA, Júnior; ARAÚJO, Tarcisio Patricio de; LIMA, Roberto Alves de (Orgs.). Fortaleza: IDT, 2016, p. 11-26.

REAL, Giselle Cristina Martins. Avaliação e qualidade no Ensino Superior: os impactos do período 1995-2002. Educação e Pesquisa. [online]. 2009, vol.35, n.3, p. 573-584. Disponível em: < http://www. scielo.br/pdf/ep/v35n3/11.pdf>. Acesso em: 10 ago. 2014.

RIBEIRO, Carlos Antônio Costa. Desigualdade de Oportunidades e Resultados Educacionais no Brasil. DADOS, Revista de Ciências Sociais, Rio de Janeiro, v. 54, n.1, 2011, p. 41-87.

RIBEIRO, Carlos Antônio Costa. Quatro Décadas de Mobilidade Social no Brasil. DADOS, Revista de Ciências Sociais, Rio de Janeiro, v.55, n.3, 2012, p.641679.

\section{ROCHA-DE-OLIVEIRA, Sidinei; PICCININI,} Valmíria Carolina. A Constituição do Trabalho na Sociedade Moderna. In: PICCININI, V. C.; ALMEIRA, M.L.; ROCHA-DE-OLIVEIRA, S. (Orgs). Sociologia e Administração: relações sociais nas organizações. Rio de janeiro: Elsevier, 2011.

Contribuições das abordagens

francesas para o estudo da inserção profissional.

Revista Brasileira de Orientação Profissional, Jan./Jun., vol. 13, n. 1, 2012a, p. 63-73.

\section{Uma Análise sobre a Inserção}

Profissional de Estudantes de Administração no

Brasil. Revista de Administração Mackenzie, v. 13, n. 2. SÃO PAULO, SP: mar/abr, 2012b, p. 44-75.

ROCHA-DE-OLIVEIRA, Sidinei; PICCININI, Valmíria Carolina; BITENCOURT, Betina Magalhães. Juventudes, Gerações e Trabalho: é possível falar em Geração Y no Brasil? In: Organizações e Sociedade. Salvador, v. 19, n. 62, julho/setembro 2012, p. 551558.

ROCHA, Sônia. A inserção dos Jovens no mercado de Trabalho. Cadernos CRH. 2008, v.21, n.54, p. 533550.
SCALON, Maria Celi. Ensaios de Estratificação. Com colaboração de ARAÚJO, Clara; MARQUES, Maria Aparecida Oliveira. Belo Horizonte: Argvmentvm, 2009, 152p.

SCHULTZ, Theodore W. O Valor Econômico da Educação. Tradução: Werneck, P. S. Rio de Janeiro: Zahar Editores, 1973, 101p.

SEGENREICH, Stella Cecilia Duarte; CASTANHEIRA, Antonio Mauricio. Expansão, privatização e diferenciação da educação superior no Brasil pós - LDBEN/96: evidências e tendências. Ensaio: aval. pol. públ. Educ., Rio de Janeiro, v. 17 , n. 62 , p. $55-86$, jan./mar. 2009. Disponível em: <http://www.scielo.br/pdf/ensaio/v17n62/ a04v1762.pdf>. Acesso em: 02 jul. 2014.

SILVA, Marcelo Almeida de Carvalho; COSTA, Alessandra de Sá Mello; LEMOS. Ana Heloisa da Costa. Ameaças, Promessas, Recomendações? A Contribuição de uma Popular Revista de Negócios para a Construção Ideológica do Discurso sobre Empregabilidade. EnEO, VIII, Gramado/RS, 2014.

SMANIOTTO, Sandra R. Uliano; MERCURI, Elizabeth. Cursos Superiores de Tecnologia: um estudo do impacto provocado em seus estudantes. B. Téc. Senac: a R. Educ. Prof., Rio de Janeiro, v. 33, n.2, maio/ago. 2007, p. 71-79. Disponível em: <http://www.senac.br/BTS/332/artigo-6.pdf>. Acesso em: 15 jul. 2014.

SOARES, Rodrigo Reis; Gustavo GONZAGA. Determinação de salários no Brasil: dualidade ou não-linearidade no retorno à educação? Rio de Janeiro: Ipea, dez. 1997. (Texto para Discussão, n.38).

SOUZA, Jessé. A Construção Social da

Subcidadania. Para uma sociologia política da modernidade periférica. 2. Ed. Belo Horizonte: Editora UFMG, 2006.

SOUZA, Jessé. Os Batalhadores e a Transformação do Brasil. In: SOUZA, Jessé (Org). Os

Batalhadores Brasileiros: nova classe média ou nova classe trabalhadora? 2. Ed. Belo Horizonte: Editora UFMG, 2012, p. 9-57.

SPOSITO, Marilia Pontes. Algumas reflexões e muitas indagações sobre as relações entre juventude e escola no Brasil. In: ABRAMO, Helena Wendel; BRANCO, Pedro Paulo Martoni (Orgs.). Retratos da Juventude Brasileira: análises de uma pesquisa nacional. São Paulo: Instituto Cidadania e Editora Fundação Perseu Abramo, 2005, p. 87-127. 
TAKAHASHI, Adriana Roseli Wünsch. Cursos superiores de tecnologia em gestão: reflexões e implicações da expansão de uma (nova) modalidade de ensino superior em administração no Brasil. Revista de Administração Pública. RAP. Rio de Janeiro: v. 44, n. 2, mar./abr. 2010, p.385-41.

TAVARES, Maria das Graças Medeiros; OLIVEIRA, Maria Antonieta Albuquerque de; SEIFFERT, Otília Maria Lúcia Barbosa. Avaliação da educação superior na revista Ensaio: Avaliação e Políticas Públicas em Educação: ênfases e tendências. Ensaio: avaliação e políticas públicas em educação. Educação. [online]. 2011, vol.19, n. 71, p. 233-258. Disponível em: < http:// www.scielo.br/scielo.php?script=sci_arttext_ pr\&pid $=$ S0104-40362011010300001 $>$. Acesso em: 06 ago. 2014.

TOMIZAKI, K. Transmitir e herdar: o estudo dos fenômenos educativos em uma perspectiva intergeracional. Educação \& Sociedade, v. 31, p. 327-346, 2010.

VERLEY, Elise; ZILLONIZ, Sandra. L'enseignement supérieur en France: un espace segmenté qui limite l'égalisation des chances 2010. Formation emploi, n. 110, 2010, p. 5-18.

VOLKMER MARTINS, Bibiana; ROCHA-DEOLIVEIRA, Sidinei. Expansão e Diversificação do Ensino Superior, Impactos no Mercado de Trabalho e Inserção Profissional no Brasil: reflexões iniciais e proposta de agenda de pesquisa. In: Anais do VI EnAPG. Belo Horizonte: EnAPG, 2014, p. 1-16.

VOLKMER MARTINS, Bibiana. Expansão e Diversificação do Ensino Superior no Brasil: a mobilidade social e a inserção profissional dos jovens estudantes e egressos de cursos superiores tecnológicos na região metropolitana de Porto Alegre-RS. 2016. 435 f. Tese (Doutorado em Administração) - Programa de Pós-Graduação em Administração, Escola de Administração, Universidade Federal do Rio Grande do Sul, Porto Alegre, 2016. 